\title{
Comparative Analysis of Methods for Determining Cyclic Properties of Metals
}

\author{
Stanisław Mroziński ${ }^{1, a^{*}}$, Zbigniew Lis $^{1, b}$ \\ ${ }^{1}$ University of Technology and Life Sciences, Faculty of Mechanical Engineering, Kaliskiego 7 , \\ 85-789, Bydgoszcz, Poland \\ astanislaw.mrozinski@utp.edu.pl, 'zbigniew.lis@utp.edu.pl
}

Keywords: Low-Cycle Properties; Fatigue Life; P91 Steel X10CRMOVNB9-1

\begin{abstract}
The study compares several methods for determining material data required for fatigue life calculation. The test methods were compared at ambient temperature $\left(T=20^{\circ} \mathrm{C}\right)$ and increased temperature $\left(T=600^{\circ} \mathrm{C}\right)$. The results show the applicability of simplified methods for determining material data.
\end{abstract}

\section{Introduction}

A series of fatigue tests is usually required to determine low-cycle fatigue properties of metals. Technical details of the tests and the results are included in [1,2], however, due to low loading frequencies and high cost of equipment, those tests are both costly and time consuming.

A simplified method for determining static properties is a stepwise increasing load testing procedure - Lo-Hi $[3,4]$. The procedure involves loading a single specimen with a programmable load, where the load is increased after a certain number of cycles (Fig. 1). Despite many disadvantages [5], the simplified method for determining cyclic properties is commonly used in practice. Its main advantages are simplicity and quick availability of the results. Stepwise increasing load testing is usually carried out under constant total strain ( $\varepsilon_{a c}=$ const) or constant plastic strain $\left(\varepsilon_{a p}=\right.$ const). An advantage of the tests carried out in those conditions is lack of material flow which can be observed in tests under $\sigma_{a}=$ const. The test conditions used depend on the intended use of the material data [6].

a)

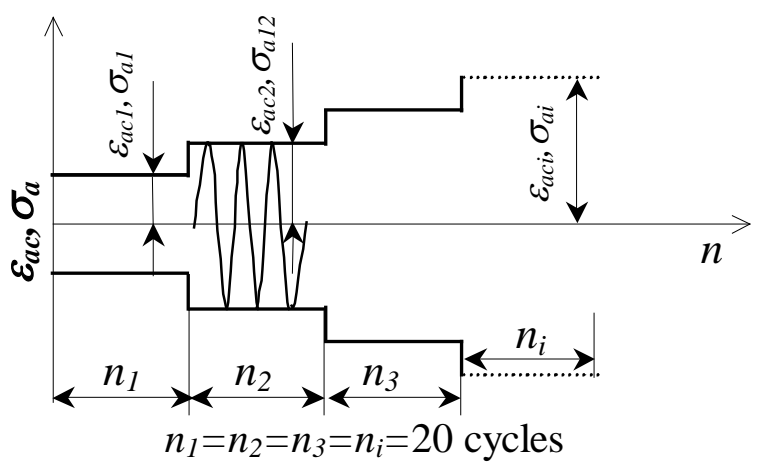

b)

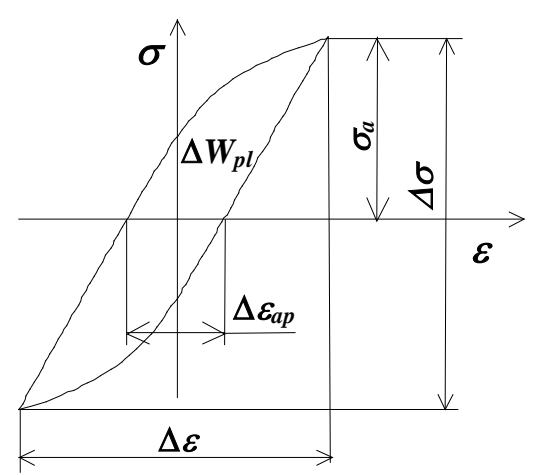

Fig. 1. Increasing load test under $\varepsilon_{a c}=$ const and $\sigma_{a}=$ const (a), parameters of the hysteresis loop (b).

The study aimed to determine the effects of the method used and the test conditions for P91 steel on material data used for fatigue life calculations. The scope includes low-cycle fatigue 
tests at $T=20^{\circ} \mathrm{C}$ and $T=600^{\circ} \mathrm{C}$ under two loading conditions ( $\varepsilon_{a c}=$ const and $\sigma_{a}=$ const $)$. Standard analytical models proposed in [1,2] were used in the comparative analysis of the test results.

\section{Analytical characteristics of the hysteresis loop}

The basic characteristic describing cyclic properties is a relationship between stress and strain - a cyclic stress-strain curve. The curve can be obtained from experimental data by connecting the peaks of stabilized hysteresis loops obtained at different strain levels. Different models are used to analytically characterize the curve, including a commonly used Ramberg - Osgood model [7]:

$$
\frac{\Delta \varepsilon}{2}=\frac{\Delta \sigma}{2 E}+\left(\frac{\Delta \sigma}{2 K^{\prime}}\right)^{\frac{1}{n^{\prime}}}
$$

$n^{\prime}$ and $K^{\prime}$ parameters are determined in fatigue tests $[1,2]$, whereas the material constant $E$ is determined in static tensile test. The method for determining $n^{\prime}$ and $K^{\prime}$ parameters assumes that plastic strain amplitude $\varepsilon_{a p}$ is an exponential function of stress amplitude $\sigma_{a}$ and can be expressed as:

$$
\varepsilon_{a p}=\left(\frac{\sigma_{a}}{K^{\prime}}\right)^{\frac{1}{n^{\prime}}}
$$

The literature also includes other characteristics of the cyclic stress-strain curve using single or two-parameter models [8]. The study focuses on $n$ ' and $K$ ' parameters of the model expressed as (1). The equation of an ascending branch of the hysteresis loop can be obtained by multiplying the relationship (1) by 2 :

$$
\Delta \varepsilon=\frac{\Delta \sigma}{E}+2\left(\frac{\Delta \sigma}{2 K^{\prime}}\right)^{\frac{1}{n^{\prime}}}
$$

The descending branches of the hysteresis loop can be obtained using equation (3) by transforming the coordinate system to the peak of the hysteresis loop. The methods are discussed in detail in the literature [9]. The equations are used to characterize the hysteresis loops for materials showing Masing behaviour [10]. For materials showing non-Masing behaviour, a special plot formed by the upper and lower branches of the hysteresis loop [9] is used. When calculating the fatigue life, the hysteresis loop energy $\Delta W_{p l}$ is calculated after the tests under controlled stress $\left(\sigma_{a}=\right.$ const) or controlled strain $\left(\varepsilon_{a}=\right.$ const, $\varepsilon_{a p}=$ const). Using known $n^{\prime}$ and $K^{\prime}$ parameters, the energy $\Delta W_{p l}$ can be calculated for any $\Delta \sigma$ and $\Delta \varepsilon$ level:

$$
\Delta W_{p l}=\Delta \sigma \cdot \Delta \varepsilon-\frac{\Delta \sigma^{2}}{E}-4 \frac{\Delta \sigma^{\frac{1}{n^{\prime}}+1}}{\left(\left(2 K^{\prime}\right)^{\frac{1}{n^{\prime}}}\right) \cdot\left(\frac{1}{n^{\prime}}+1\right)}
$$

\section{Test method}

The fatigue test specimens were made with P91 steel (X10CRMOVNB9-1). The fatigue tests were carried out at two temperatures $T=20^{\circ} \mathrm{C}$ and $T=600^{\circ} \mathrm{C}$ under controlled strain $\varepsilon_{a c}=$ const and stress $\sigma_{a}=$ const. Constant-amplitude fatigue tests under controlled strain $\varepsilon_{a c}=$ const were carried 
out at five strain levels $\varepsilon_{a c}(0.25 ; 0.3 ; 0.35 ; 0.5 ; 0.6 \%)$. Constant-amplitude fatigue tests under $\sigma_{a}=$ const were also carried out at five stress levels. The stress levels $\sigma_{a}$ were determined based on the analysis of low-cycle fatigue test results under $\varepsilon_{a c}=$ const. Stepwise increasing load test under controlled strain $\left(\varepsilon_{a c}-\mathrm{Lo}-\mathrm{Hi}\right)$ started at $0.1 \%$. The load was increased by $0.05 \%$ every 20 cycles. Under controlled stress $\left(\sigma_{a}-\mathrm{Lo}-\mathrm{Hi}\right)$, the levels were determined based on the analysis of the results of stepwise increasing load test under $\varepsilon_{a c}$-Lo-Hi. Fig. 2 shows the method for determining stress $\left(\sigma_{a}\right)$.

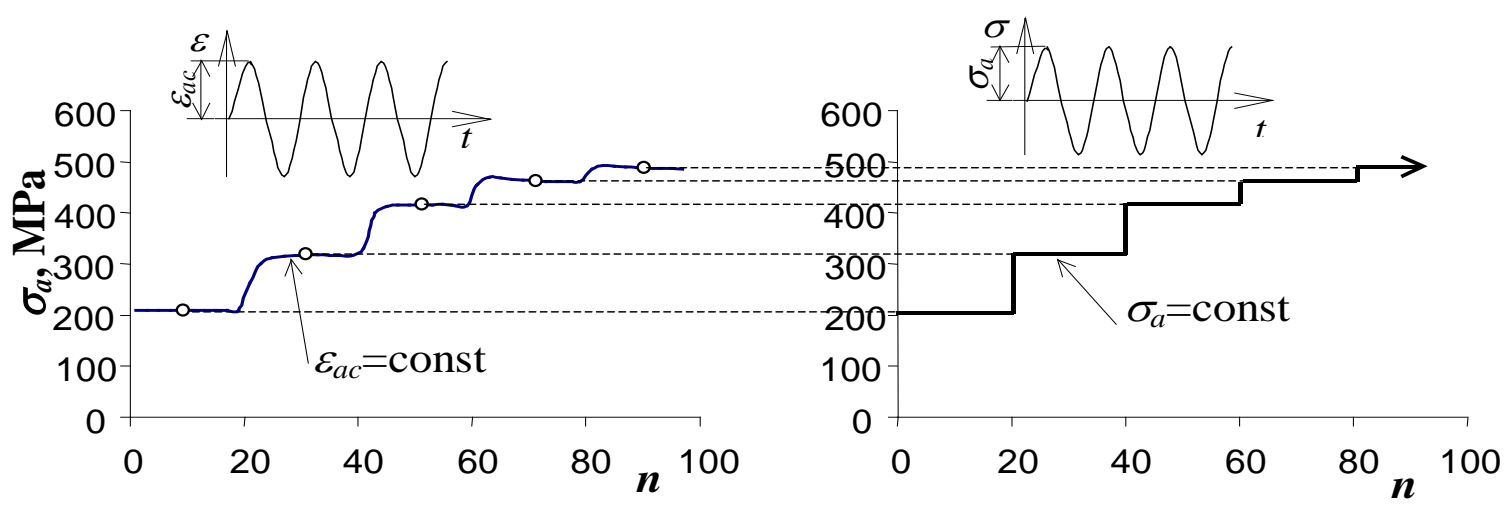

Fig. 2. Determining stress levels under $\sigma_{a}-$ Lo-Hi.

\section{Test results}

The fatigue tests show changes in the hysteresis loop parameters as a function of the number of load cycles. Fig. 3 shows changes in plastic strain $\varepsilon_{a p}$ during constant-amplitude and stepwise increasing load tests as a function of fatigue life $n / N$. Under $\sigma_{a}=$ const, the range of changes in plastic strain $\varepsilon_{a p}$ is significantly higher than the range $\varepsilon_{a p}$ observed under $\varepsilon_{a c}=$ const. It applies to both constant-amplitude tests (Fig. 3a) and stepwise increasing load tests (Fig. 3b).

a)

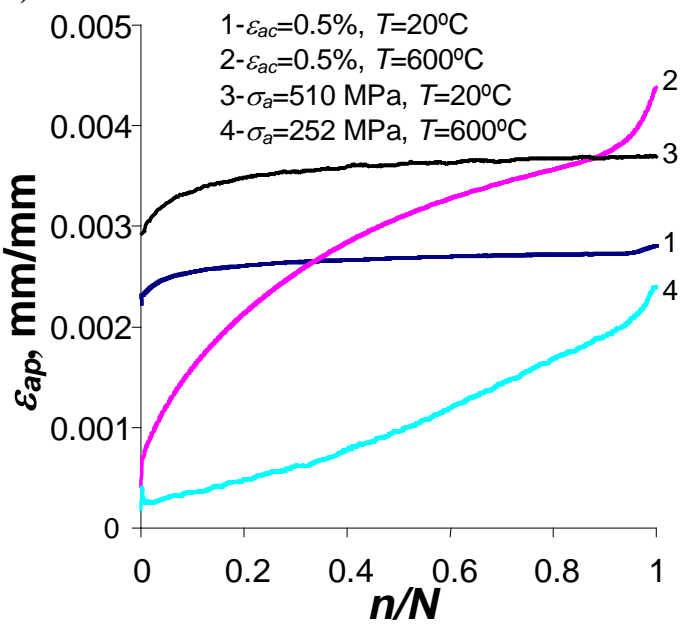

b)

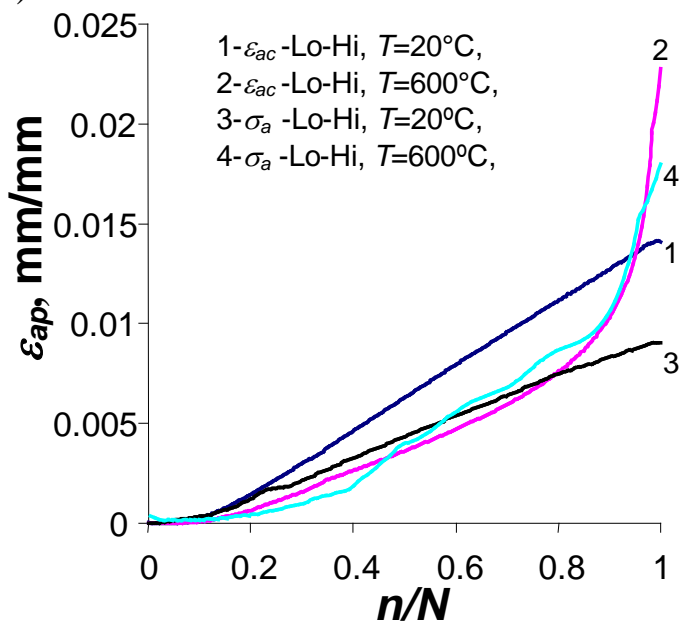

Fig. 3. Changes in $\varepsilon_{a p}$ : a) constant-amplitude tests; b) stepwise increasing load tests. 


\section{$n$ ' and $K^{\prime}$ material parameters}

Cyclic stress-strain curve parameters (equation 2, $n^{\prime}$ and $K^{\prime}$ ) were determined for $0.5 n / N$. For tests with stepwise increasing load it corresponds to half of the number of cycles for a single stage. $\sigma_{a}$ and $\varepsilon_{a p}$ were approximated by regression lines (2) and shown in Fig. 4.

a)

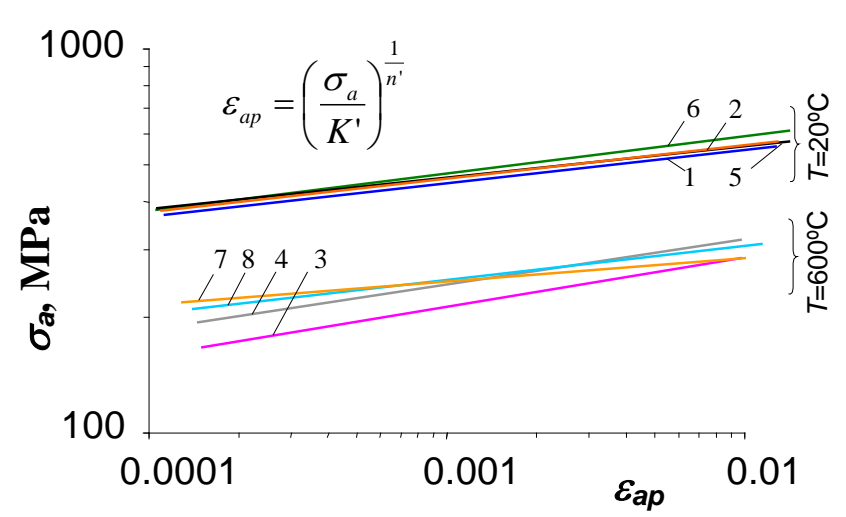

b)

\begin{tabular}{|c|l|c|c|}
\hline No & \multicolumn{1}{|c|}{ Methods } & $n^{\prime}$ & $K^{\prime}, \mathrm{MPa}$ \\
\hline 1 & $\varepsilon_{a c}=$ const. $T=20^{\circ} \mathrm{C}$ & 0.0894 & 831.0 \\
\hline 2 & $\sigma_{a}=$ const. $T=20^{\circ} \mathrm{C}$ & 0.0863 & 835.8 \\
\hline 3 & $\varepsilon_{a c}=$ const. $T=600^{\circ} \mathrm{C}$ & 0.1248 & 508.7 \\
\hline 4 & $\sigma_{a}=$ const. $T=600^{\circ} \mathrm{C}$ & 0.1681 & 787.5 \\
\hline 5 & $\varepsilon_{a c}$-Lo-Hi. $T=20^{\circ} \mathrm{C}$ & 0.0910 & 871.5 \\
\hline 6 & $\sigma_{a}$-Lo-Hi. $T=20^{\circ} \mathrm{C}$ & 0.0973 & 929.4 \\
\hline 7 & $\varepsilon_{a c}$-Lo-Hi. T $=600^{\circ} \mathrm{C}$ & 0.0613 & 377.5 \\
\hline 8 & $\sigma_{a}$-Lo-Hi. $T=600^{\circ} \mathrm{C}$ & 0.0873 & 458.0 \\
\hline
\end{tabular}

Fig. 4. Cyclic stress-strain curves a) graphical representation; b) n' and K' parameters.

The tests showed that at $T=20^{\circ} \mathrm{C}$ and $T=600^{\circ} \mathrm{C}$, the relationship between strain $\varepsilon_{a p}$ and stress $\sigma_{a}$ (2) to a lesser degree depends on the loading conditions. It can be verified by similar $n$ ' and $K$ ' parameter values. The statistical analysis included a parallelism test and an absolute term test of the regression lines (2) for different loading conditions. The tests show that there are no grounds to reject the hypothesis about the equality of slopes $n$ ' and absolute term $K$ ' of the analysed regression lines. It verifies the applicability of a simplified test to determine cyclic properties.

\section{Experimental verification of the analytical characteristics of the hysteresis loop}

Figs 5 and 6 shows the example hysteresis loops for two strain levels $\left(\varepsilon_{a c}=0.5 \%, 0.6 \%\right)$ at $T=20^{\circ} \mathrm{C}$ and $T=600^{\circ} \mathrm{C}$ obtained from tests and calculations. An equation of the descending and ascending branches of the hysteresis loop was obtained by transforming equation (1).

a)

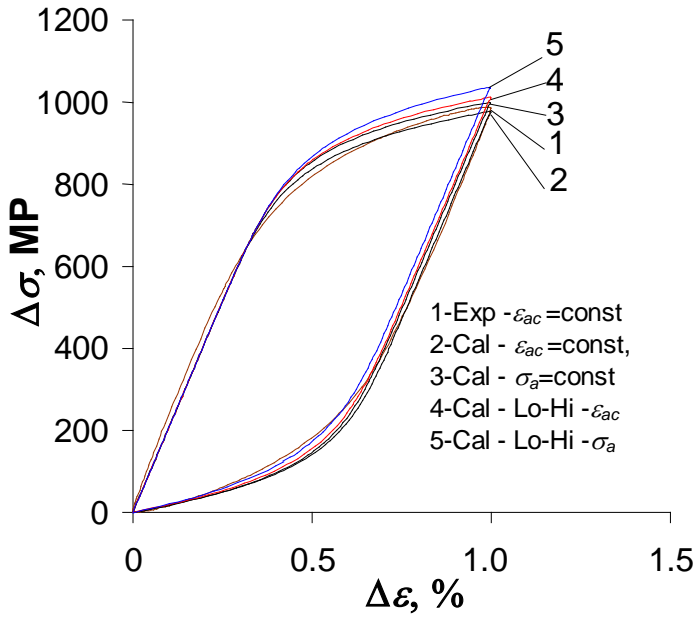

b)

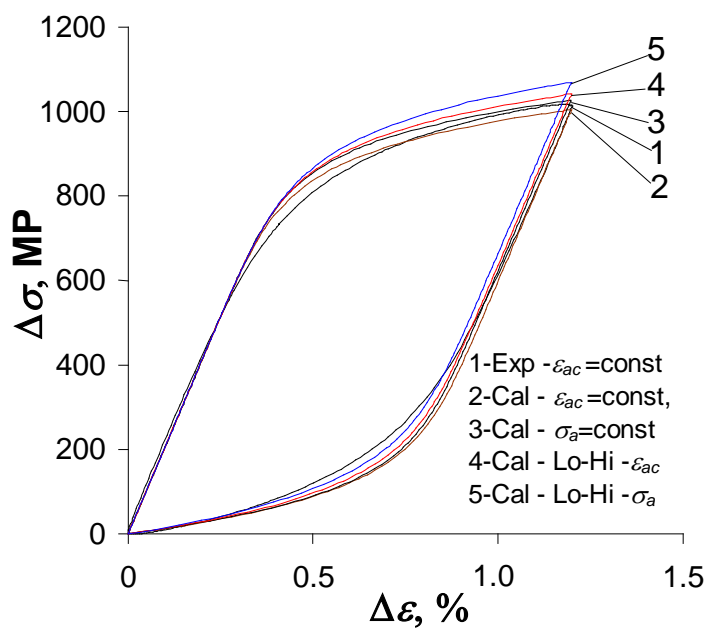

Fig. 5. Hysteresis loops obtained from tests and calculations at $T=20^{\circ} \mathrm{C}$ a) $\varepsilon_{a c}=0.5 \%$; b)

$$
\varepsilon_{a c}=0.6 \% \text {. }
$$


a)

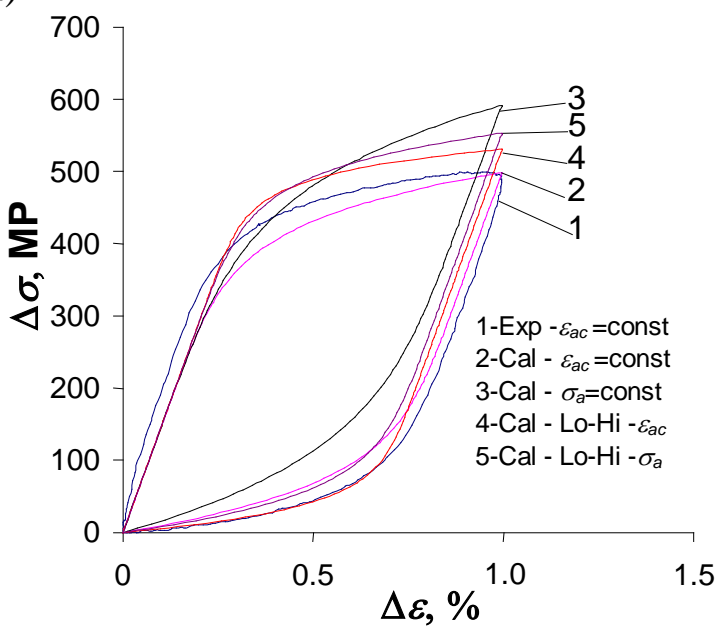

b)

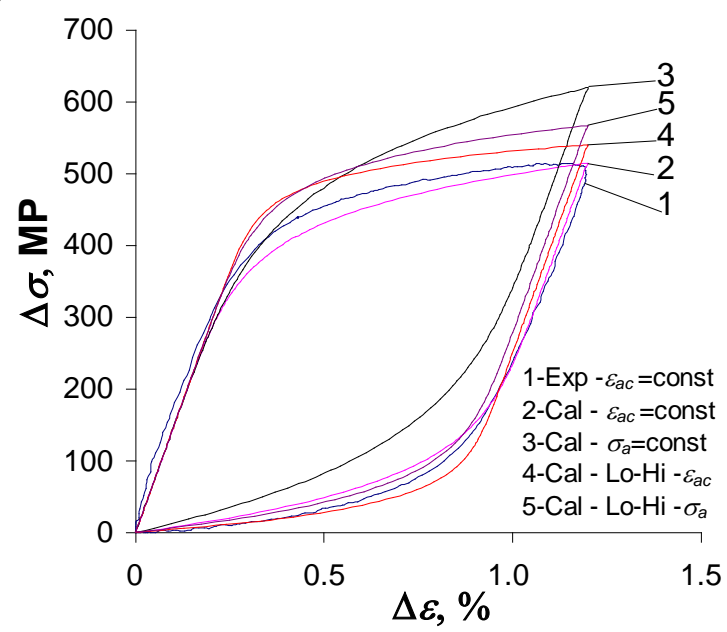

Fig. 6. Hysteresis loops obtained from tests and calculations at $T=600^{\circ} \mathrm{C}$ a) $\varepsilon_{a c}=0.5 \%$; b)

$$
\varepsilon_{a c}=0.6 \% \text {. }
$$

Observed differences in equation (2) parameters (Fig. 5 and 6) resulted in different hysteresis loops. The difference in shape of the hysteresis loops is affected both by temperature and loading conditions during determination of $n$ ' and $K^{\prime}$ parameters.

A comparative analysis of the hysteresis loops obtained from calculations and tests at $T=20^{\circ} \mathrm{C}$ and $T=600^{\circ} \mathrm{C}$ shows larger differences between loops obtained from calculations and tests at $T=600^{\circ} \mathrm{C}$. Larger differences between the loop obtained from tests and the loop obtained from calculations can be explained by larger changes in loop parameters as a function of the number of loading cycles (Fig. 3).

Coefficient $\delta=\Delta W_{\text {pl(exp) }} / \Delta W_{p l(\text { cal })}$ was calculated to qualitatively compare methods for determining $n$ ' and $K^{\prime}$ parameters, where: $\Delta W_{\text {pl(ехр) }}$ is the hysteresis loop energy obtained from tests and $\Delta W_{p l(c a l)}$ - is the energy obtained from calculations. Energy $\Delta W_{p l(c a l)}$ was calculated from (4) and the material data determined under different loading conditions. The hysteresis loop energy was calculated for five different strain levels during constant-amplitude tests under $\varepsilon_{a c}=$ const. Fig. 7 shows the $\delta$ coefficient values.

a)

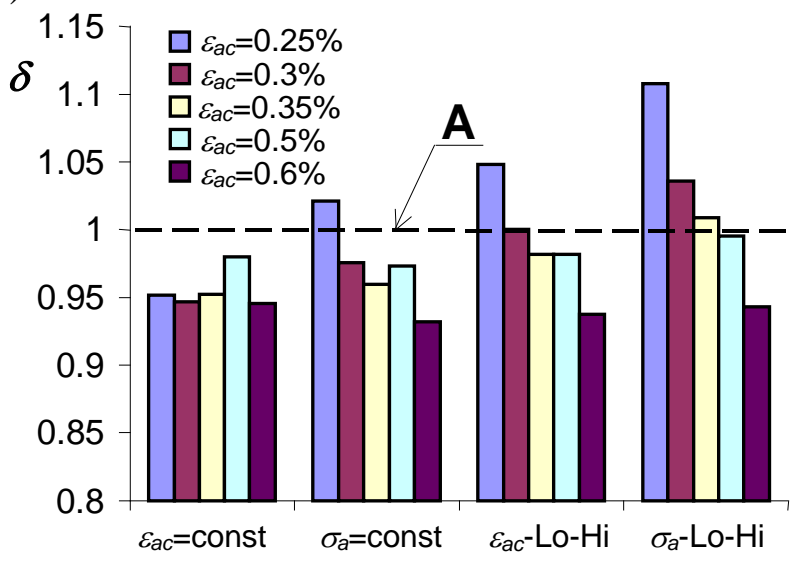

b)

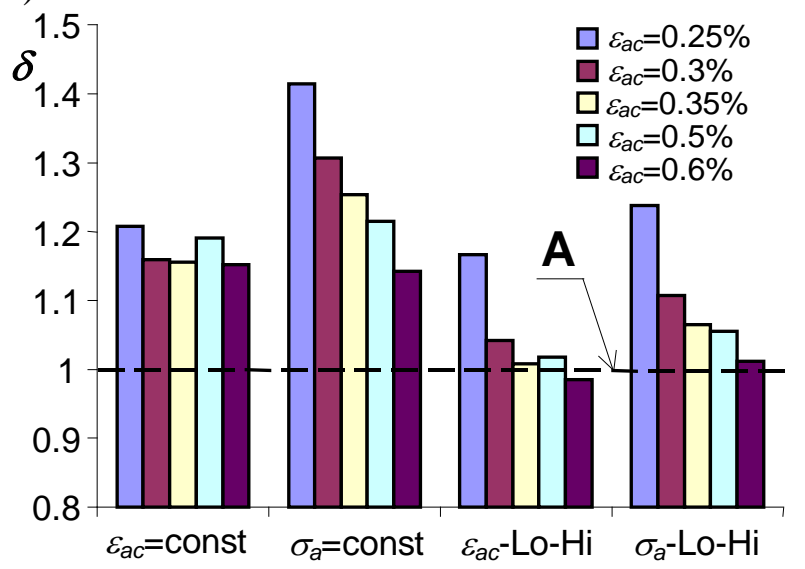

Fig. 7. Coefficient $\delta$ : a) $\mathrm{T}=20^{\circ} \mathrm{C}$, b) $\mathrm{T}=600^{\circ} \mathrm{C}$. 
Coefficients $\delta$ equal to one (line A) indicate that the energy $\Delta W_{\text {pl(exp) }}$ obtained from tests at a certain $\varepsilon_{a c}=$ const level is equal to the energy $\Delta W_{p l(c a l)}$ obtained from calculations and shows the consistency of calculation and test results. The analysis of coefficient $\delta$ shows that the test method providing very good representation of the test results cannot be clearly identified. A comparative analysis of $\delta$ coefficient at ambient and increased temperature shows that the effectiveness of analytical models describing the hysteresis loop is higher at $T=20^{\circ} \mathrm{C}$ than at $T=600^{\circ} \mathrm{C}$. $\delta$ coefficient values show that at $T=20^{\circ} \mathrm{C}$, for a majority of strain levels, $\Delta W_{p l(\text { cal })}>\Delta W_{\text {pl(exp })}$, whereas at $T=600^{\circ} \mathrm{C}$, the opposite is true $\Delta W_{\text {pl(cal) }}<\Delta W_{\text {pl(exp) }}$.

\section{Summary}

The Ramberg-Osgood model - an analytical model describing cyclic properties - includes parameters determined during cyclic loading ( $n$ ' and $K^{\prime}$ ). A simplified method yields similar values for all parameters controlled throughout the test.

High similarity of the test results obtained using the simplified method (Lo-Hi tests) and the standard method (constant-amplitude tests) shows the applicability of the results obtained using the simplified method for initial calculations and choosing structural features if comprehensive fatigue characteristics are not available.

The material data determined using the simplified method can be used repeatedly when calculating fatigue life [11]. It means, that even the slightest differences in $\Delta W_{p l}$ energy obtained from calculations and tests may lead to accumulation of small differences and thus to significant differences between the results obtained from calculations and tests.

This publication is financed by the National Science Centre as part of the research project no. 2017/25/B/ST8/02256

\section{References}

[1] PN-84/H-04334 Low-cycle fatigue test for metals.

[2] ASTM E606-92: Standard Practice for Strain - Controlled Fatigue Testing.

[3] S. Mroziński, Analiza porównawcza dwóch metod wyznaczania własności cyklicznych metali, Przegląd Mechaniczny Nr 4 (2004) 30-36.

[4] S. Kocańda, A. Kocańda, Low-cycle fatigue strength of metals, PWN Warsaw (1989).

[5] M. Bayerlein, H. Christ, H. Mughrabi, A critical evaluation of the incremental step test, II International Conference on Low Cycle Fatigue and Elasto-Plastic Behaviour of Materials, Munich (1987) 149-153. https://doi.org/10.1007/978-94-009-3459-7_22

[6] S. Mroziński, H. Egner, M. Piotrowski, Effects of fatigue testing on low-cycle properties of P91 steel, International Journal of Fatigue 120 (2019) 65-72.

https://doi.org/10.1016/j.ijfatigue.2018.11.001

[7] W. Ramberg, W.R. Osgood, Description of stress-strain curves by three parameters, NACA, Tech.Note, No 402, (1943).

[8] J. Kaleta, Experimental basics of energy-based fatigue hypotheses, Oficyna Wydawnicza Politechniki Wrocławskiej, Monograph no. 24, (1998). 
[9] F. Ellyin, D. Kujawski, Plastic strain energy in fatigue failure, J. Pressure Vessel Technology, Trans. ASME 106 (1984) 342-347. https://doi.org/10.1115/1.3264362

[10] Z. Zhang, Z. Hu, S. Schmauder, M. Mlikota K. Fan, Low-Cycle Fatigue Properties of P92 Ferritic-Martensitic Steel at Elevated Temperature, Journal of Materials Engineering and Performance Volume 25 (2016) 1650-1662. https://doi.org/10.1007/s11665-016-1977-8

[11] D.G. Pavlou, The theory of the S-N fatigue damage envelope: generalization of linear, double linear, and non-linear fatigue damage models. International Journal of Fatigue, 110 (2018) 204-214. https://doi.org/10.1016/j.ijfatigue.2018.01.023 